\title{
Mesenchymal stem cells rescue cardiomyoblasts from cell death in an in vitro ischemia model via direct cell-to-cell connections
}

\author{
Attila Cselenyák*, Eszter Pankotai, Eszter M Horváth, Levente Kiss and Zsombor Lacza
}

\begin{abstract}
Background: Bone marrow derived mesenchymal stem cells (MSCs) are promising candidates for cell based therapies in myocardial infarction. However, the exact underlying cellular mechanisms are still not fully understood. Our aim was to explore the possible role of direct cell-to-cell interaction between ischemic H9c2 cardiomyoblasts and normal MSCs. Using an in vitro ischemia model of 150 minutes of oxygen glucose deprivation we investigated cell viability and cell interactions with confocal microscopy and flow cytometry.
\end{abstract}

Results: Our model revealed that adding normal MSCs to the ischemic cell population significantly decreased the ratio of dead H9c2 cells (H9c2 only: $0.85 \pm 0.086$ vs. H9c2+MSCs: $0.16 \pm 0.035$ ). This effect was dependent on direct cell-tocell contact since co-cultivation with MSCs cultured in cell inserts did not exert the same beneficial effect (ratio of dead H9c2 cells: $0.90 \pm 0.055$ ). Confocal microscopy revealed that cardiomyoblasts and MSCs frequently formed 200-500 nm wide intercellular connections and cell fusion rarely occurred between these cells.

Conclusion: Based on these results we hypothesize that mesenchymal stem cells may reduce the number of dead cardiomyoblasts after ischemic damage via direct cell-to-cell interactions and intercellular tubular connections may play an important role in these processes.

\section{Background}

Cardiovascular diseases represent an enormous medical and social burden $[1,2]$ and the pathophysiology of most of these diseases, such as myocardial infarction or heart failure, involves death of cardiac myocytes leading to a loss of functional tissue. Cell based therapies are commonly believed to be the next generation of therapies for replacing such lost tissue [3-5]. Several in vivo animal and human studies have found that implantation of various cell types, typically bone marrow derived stem cells, into damaged myocardium improved cardiac performance. Also where the experimental protocol allowed, surviving grafted cells were detected in the myocardium [6,7], suggesting that grafting is an effective treatment of acute myocardial infarction [8]. However, the extent of the beneficial effect, the optimal cell type and number, the best

\footnotetext{
* Correspondence: attila.cselenyak@tissueengineering.hu

1 Institute of Human Physiology and Clinical Experimental Research, Semmelweis University, H-1094, Tűzoltó utca 37-47, Budapest, Hungary Full list of author information is available at the end of the article
}

method of administration, and the mechanism of action need to be further evaluated [9].

One important issue is the exact mechanism of action, in other words, the interaction between graft and host. Paracrine factors, transdifferentiation and cell fusion are the three generally accepted hypotheses explaining the beneficial effects of stem cell grafting. Paracrine factors through various effects, such as increased angiogenesis or modulation of postinfarct remodeling, may represent an important aspect of the benefits $[10,11]$. On the other hand, several studies have found that co-culture of cardiomyocytes with pluripotent stem cells resulted in transdifferentiation of these cells into cardiomyocytes, which raised the hope that in vitro cultured tissue blocks can later be used for cardiac repair [12,13]. However, although it is possible to construct a tissue in vitro this does not mean that its building blocks will perform similarly when implanted in vivo [14]. Indeed, recent investigations found difficult to reproduce transdifferentiation and that bone marrow derived cells generate cardiomyocytes not by transdifferentiation but rather through cell 
fusion $[15,16]$. Alvarez-Dolado et al demonstrated that bone marrow derived cells fused with cardiomyocytes [17], but the importance of cell fusion events was questioned by an other investigation [18]. Even in studies which found morphologically adequate new cardiomyocytes, the volume of this newly formed tissue seemed to be inadequate to account for the functional benefits. Other hypotheses have also emerged to resolve the apparent controversy among the clinical findings and the cell culture studies, such as the most recently proposed partial cell fusion through direct cell-to-cell interactions. This novel intercellular communication route depends on short cell-to-cell interactions, during which the two connected cells exchange membrane and organelle parts such as mitochondria or other cytoplasmatic components [19]. Recently, it was reported that cardiomyocytes and human mesenchymal stem cells appear to communicate through small diameter nanotubes, and mitochondria can migrate from MSCs to cardiomyocytes [20]. However, the physiological purpose of this constantly changing nanotubular network and its possible role during ischemic conditions is unclear. We hypothesized that stem cells and post-ischemic cardiomyoblasts interact with each other via this novel mechanism and that this mechanism may play a role in the beneficial effect of stem cell transplantation.

The aim of our study was to examine the possibility of rescuing ischemically damaged $\mathrm{H} 9 \mathrm{c} 2$ cardiomyoblasts from cell death by adding mesenchymal stem cells to the cultures after ischemia. Furthermore we investigated the importance of direct cell-to-cell interactions during cocultivation of these cells.

\section{Methods}

\section{Isolation and culture of cardiomyoblasts and MSCs}

H9c2 rat cardiomyoblasts were obtained from ATCC (Wesel, Germany) and expanded in high glucose $(4.5 \mathrm{~g} / \mathrm{L})$ DMEM containing $10 \%$ fetal bovine serum, $4 \mathrm{mM} \mathrm{L-glu-}$ tamine, $100 \mathrm{U} / \mathrm{ml}$ penicillin and $100 \mu \mathrm{g} / \mathrm{ml}$ streptomycin. Mouse mesenchymal stem cells (MSCs) were harvested from the femur of $\mathrm{C} 57 \mathrm{Bl} / 6$ mice. Isolation and primary culture was performed according to Tropel's method with small alterations [21]. Briefly, animals were anaesthetized with pentobarbital (ip, $50 \mathrm{mg} / \mathrm{kg}$, Nembutal, Ovation, Deerfield, IL, USA), lower limbs were removed and femurs were cleaned of tissue. Bone marrow was collected by flushing femurs with low glucose DMEM containing $10 \%$ fetal bovine serum, $2 \mathrm{mM} \mathrm{L}$-glutamine, 100 $\mathrm{U} / \mathrm{ml}$ penicillin and $100 \mu \mathrm{g} / \mathrm{ml}$ streptomycin. Cells were centrifuged at $1200 \mathrm{rpm}$ and plated in a T75 flask. After 4-5 days, non-adherent cells were removed by washing twice with PBS and adherent cells were then cultured in low glucose DMEM complete medium. Characterization of the cultured MSCs showed that these cells were strongly positive for the specific surface antigen Sca-1 and negative for differentiation markers of other cell lineages (CD34, CD3e, CD45R/B220, CD11b, 6G, and TER$119)$ and were able to differentiate into the osteoblast and adipocyte lineages in vitro, verifying the MSC phenotype [22]. Cell culture media was replaced every 2-3 days thereafter. All investigations conformed to the Guide for the Care and Use of Laboratory Animals published by the National Institutes of Health (NIH Publication No. 85-23, Revised 1985), and were approved by the local ethics committee.

\section{In vitro ischemia model}

Ischemia-reperfusion was simulated in vitro by performing oxygen glucose deprivation (OGD) on H9c2 cell cultures. Cells were incubated in glucose-free DMEM in an atmosphere of $0.5 \% \mathrm{O}_{2}$ and $99.5 \% \mathrm{~N}_{2}$ for 150 minutes. This procedure was performed on the stage of the confocal microscope (PECON incubation system, ErbachBach, Germany) allowing the observation of the cells during OGD. To evaluate cell viability we used calcein-AM (excitation/emission $494 / 517 \mathrm{~nm}$ ) to identify live cells, and ethidium-homodimer (excitation/emission 528/617 $\mathrm{nm})$ to stain dead or damaged cells [23].

\section{Co-cultivation of cardiomyoblasts and MSCs after OGD}

H9c2 cells and MSCs were labeled before co-cultivation with Vybrant $\mathrm{DiO}$ (excitation/emission: 488/501 nm) and DiD (excitation/emission: 633/665 nm) (Molecular Probes, USA) membrane dyes in a dilution of 1:200 according to the manufacturer's description for $30 \mathrm{~min}$ utes at $37^{\circ} \mathrm{C}$. The DiO-labeled $\mathrm{H} 9 \mathrm{c} 2$ cells were plated in 12 well-plates at a density of 30,000 cells/well in $2 \mathrm{ml}$ culture medium. Cells were subjected to 150 min OGD, then the medium was changed and 20,000 DiD-labeled MSCs/ well were added to the damaged $\mathrm{H} 9 \mathrm{c} 2$ cells 30 minutes after the end of OGD either directly or in cell culture inserts $(0.4 \mu \mathrm{m}$ pore size, Becton Dickinson, NJ, USA). H9c2 cells not receiving MSCs after OGD were used as controls. Cells were cultivated for a further 24 hours, then labeled with the dead cell stain ethidium homodimer $\left(4 \mu \mathrm{M}, 30\right.$ minutes, and $\left.37^{\circ} \mathrm{C}\right)$, then investigated either with confocal microscopy (Zeiss LSM 510 META, Carl Zeiss, Jena, Germany) or with flow cytometry (BD FACSCalibur ${ }^{\mathrm{Tw}}$, Becton Dickinson, NJ, USA).

\section{Confocal microscopy and flow cytometry}

Time lapse video microscopy was performed during and after in vitro ischemia to investigate morphological changes and possible interactions among the cells over time (1 picture/3 minutes). The H9c2 cardiomyoblasts and MSCs were co-cultured on $42 \mathrm{~mm}$ coverslips and stained with Vybrant $\mathrm{DiO}$ and $\mathrm{DiD}$, respectively. In experiments to observe mitochondria, all cells were 
stained after OGD with MitoTracker Red (Molecular Probes, USA) in a dilution of 1:2000 for 10 minutes at $37^{\circ} \mathrm{C}$ according to the manufacturer's description. Flow cytometric measurements were performed on single cell suspensions of trypsinized (0.05\% trypsin-EDTA) cell cultures 24 hours after OGD and on normal cell cultures (control) using BD FACSCalibur ${ }^{\mathrm{ru}}$. DiO-labeled H9c2 cells were identified and gated. Fluorescence data were collected using logarithmic amplification until 10,000 counts were reached.

\section{Evaluation of fluorescence images and statistical analysis}

The evaluation of confocal images for live and dead cells selected by morphology and fluorescence was performed with ImageJ software (National Institutes of Health, USA). In case of co-cultures, MSCs were distinguished from H9c2 cells due to their Vybrant DiD cell labeling. The ratio of dead cells was evaluated in 4 independent fields of view (objective 10x) for each culture in a blind fashion. The evaluation of flow cytometry files was carried out using BD CellQuest ${ }^{\text {tm }}$ Pro (Becton Dickinson, NJ, USA). Statistical analysis of data was carried out using one-way analysis of variance with Tukey's multiple comparison post hoc test. Data are expressed as mean \pm SEM.

\section{Results}

In vitro ischemia model

The optimal duration of OGD to induce cell damage was 150 minutes (Figure $1 \mathrm{~A}$ and additional file 1: video1.mov). This result is based on microscopic observations of morphological changes in the cell shape and on ethidium homodimer staining which determined whether a particular cell was dying. Flow cytometric analysis was also used to determine that the selected time interval was sufficient to injure the majority of the cardiomyoblasts (Figure 1B).

Experiments showed that 4-6 hours was not adequate for the added MSCs to attach to the surface of the 12-well plates and exert their effect, 48 hours produced a culture overgrown by cardiomyoblasts and MSCs (data not shown). Therefore, the time point for microscopic evaluation and flow cytometry analysis subsequent to addition to MSCs was determined to be 24 hours.

\section{Co-cultivation of cardiomyoblasts and MSCs after OGD}

Confocal microscopy showed that cardiomyoblasts cultured alone displayed the same rounded and blebbed morphology immediately following as well as 24 hours after OGD (Figure 2A). Flow cytometry analysis showed that OGD significantly increased the cell death rate in this group as shown by the enhanced ethidium homodimer fluorescence intensity (median fluorescence from 19 to 65 units, Figure 2B). Figure 2B also shows that a portion of cells remained unstained with ethidium homodi- mer even after 150 minutes due to the variability of the model. When MSCs were added to post-ischemic cardiomyoblasts, the morphology of the damaged cells was similar to cells cultured in normal conditions without OGD (Figure 2C). In this group, flow cytometry analysis revealed that the deleterious results of ischemia were decreased (median fluorescence 24 versus 23 units, Figure 2D). To quantify the effect of added MSCs, confocal images were used. This approach revealed that the ratio of dead H9c2 cells to all H9c2 cells in the wells 24 hours after OGD was significantly higher when the cardiomyoblasts were cultured alone compared to when healthy MSCs were added to the cultures 30 minutes after OGD $(0.85 \pm 0.086$ vs. $0.16 \pm 0.035$, respectively, $\mathrm{p}<0.05, \mathrm{n}=$ 5). MSCs added in cell culture inserts, which physically separate the two cell populations growing in the same medium, failed to decrease the ratio of dead cells $(0.90 \pm$ $0.055, \mathrm{n}=5$ ), indicating that the rescue factor is less likely to be a soluble one and direct cell-to-cell contact may be required (Figure $3 \mathrm{~A}$ and $3 \mathrm{~B}$ ). The absolute number of live H9c2 cells before and after OGD and the number of added MSCs after OGD was also investigated. Before OGD H9c2 cells were close to confluence $(63,120 \pm$ $7,694)$ and there was little increase in cell numbers during the next 24 hours if the cells were left to grow without OGD $(76,116 \pm 3,396)$. The number of viable cells 24 hours after OGD was very low when cultured alone or with MSCs in cell insert $(1,757 \pm 1,081$ and $990 \pm 608$ respectively), but significantly increased $(15,174 \pm 3,975)$ if MSCs were added directly. It can be assumed that the injured $\mathrm{H} 9 \mathrm{c} 2$ cells were washed out during medium change so only a part of $\mathrm{H} 9 \mathrm{c} 2$ cells remained in the wells (Figure 3C). We also examined the inserts with confocal microscopy to eliminate the possibility of decreased MSC viability on the cell culture inserts. MSCs were labeled with Vybrant DiD before seeding on the cell inserts. We found that Vybrant DiD labeled MSCs were attached to the surface of the inserts and showed normal cell morphology (Figure 3D). We also investigated whether any of the MSCs had contaminated the underlying H9c2 cardiomyoblast culture, but found no trace of MSCs among the H9c2 cells; therefore no direct cell-to-cell contact could be formed (data not shown).

\section{Confocal microscopy and flow cytometry}

Development of intercellular connections, so-called nanotubes, between cardiomyoblasts and MSCs during the $24 \mathrm{hr}$ period after OGD was frequently observed (Figure $4 \mathrm{~A})$. These nanotubes were long enough to span distances of several cell diameters, and their diameters were between 200 and $500 \mathrm{~nm}$. MitoTracker Red staining revealed that these nanotubes connecting stem cells to cardiomyoblasts contained functionally active mitochondria (Figure 4B). Time lapse video microscopy did not 


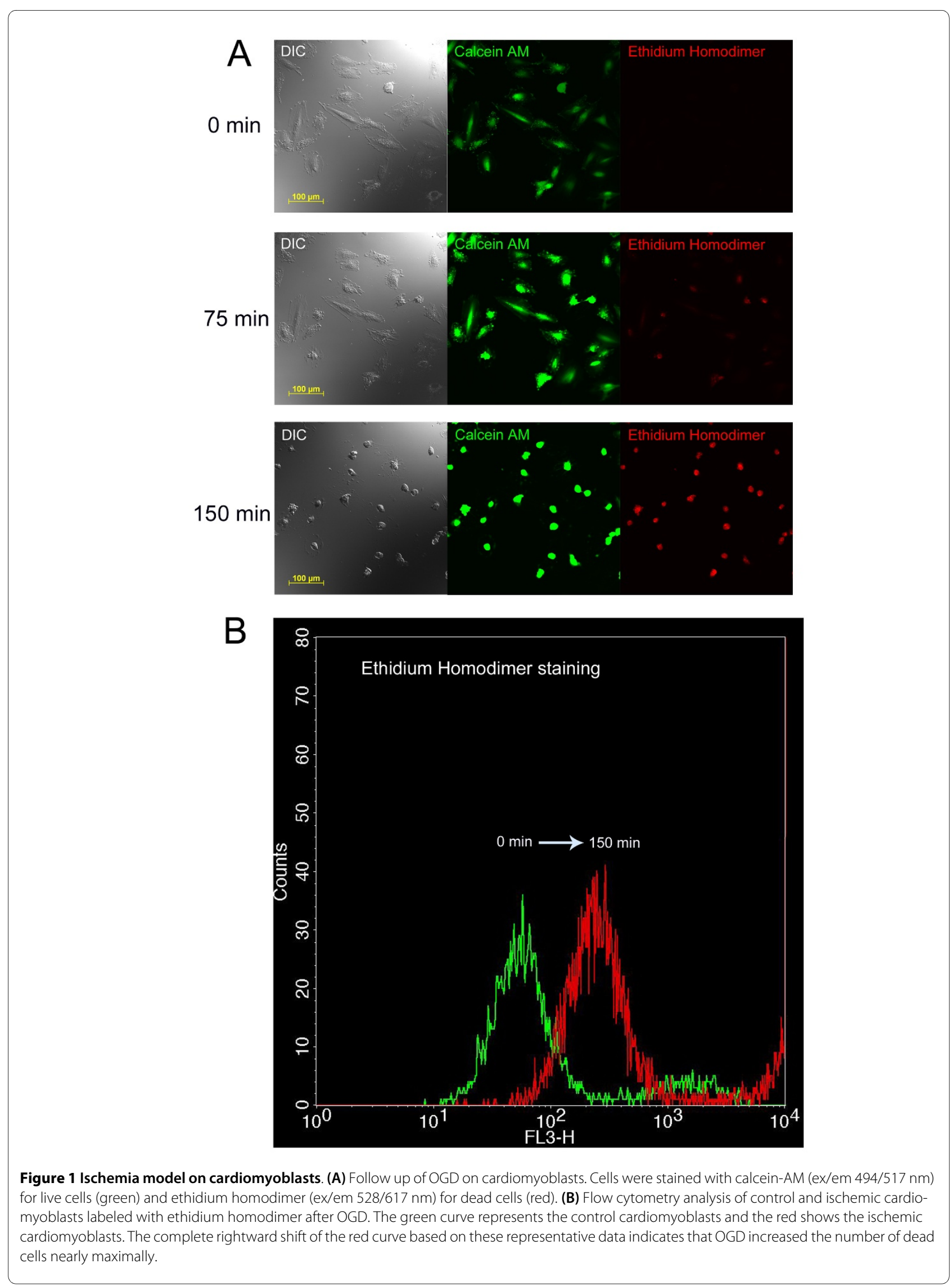




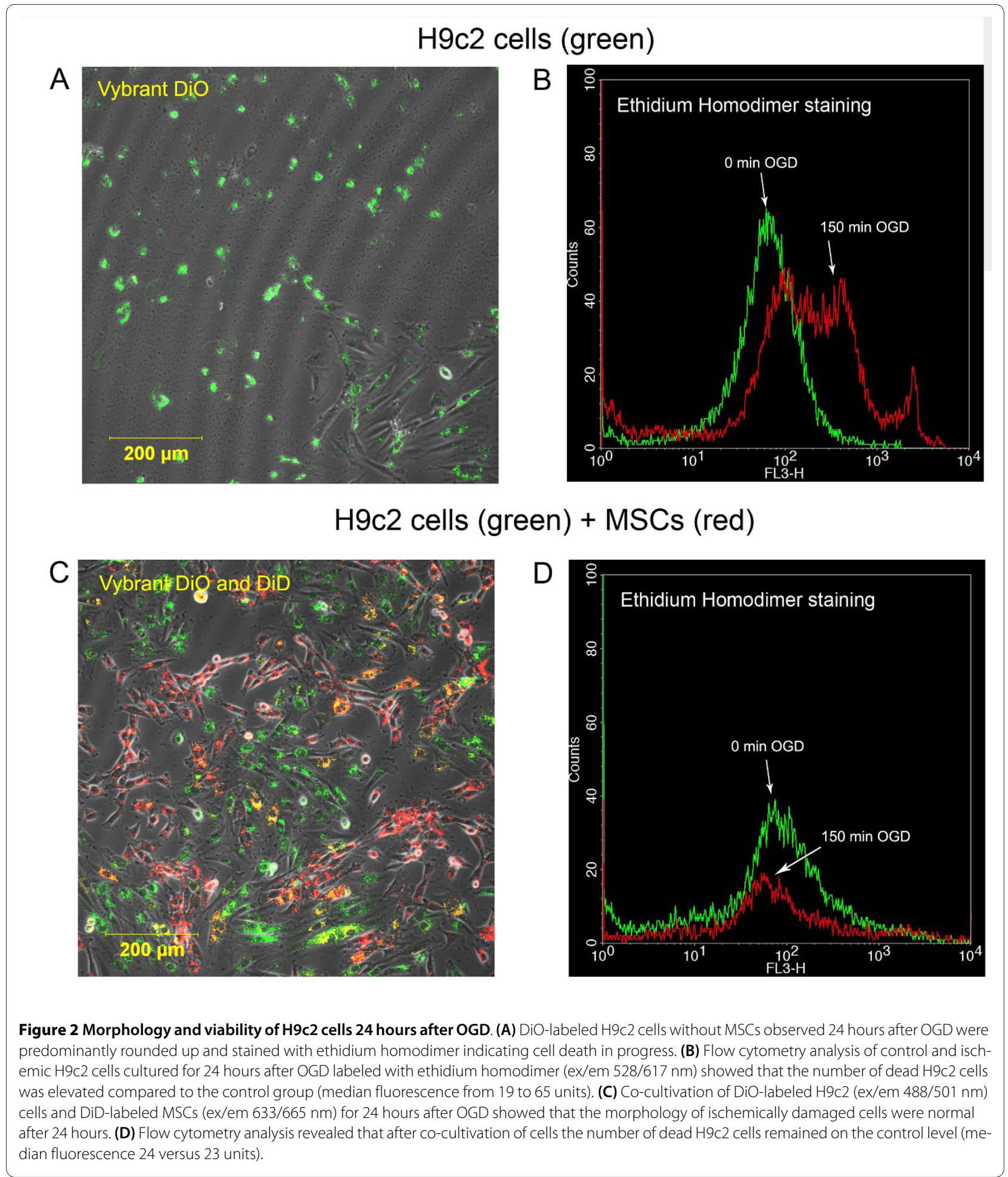

reveal a specific direction for the movement of these mitochondria in the intercellular connections and the typical time frame for the formation of a nanotube was approximately 2 hours (Figure $4 \mathrm{C}$ and additional file 2: video2.mov).
Addition to the formation of intercellular communications, double labeled and double nuclei cells indicated that cell fusion events were present in the co-cultures. The typical time frame for a cell fusion was approximately 4 hours (Figure 5 and additional file 3: video3.mov). To examine whether cell fusion occurs in 

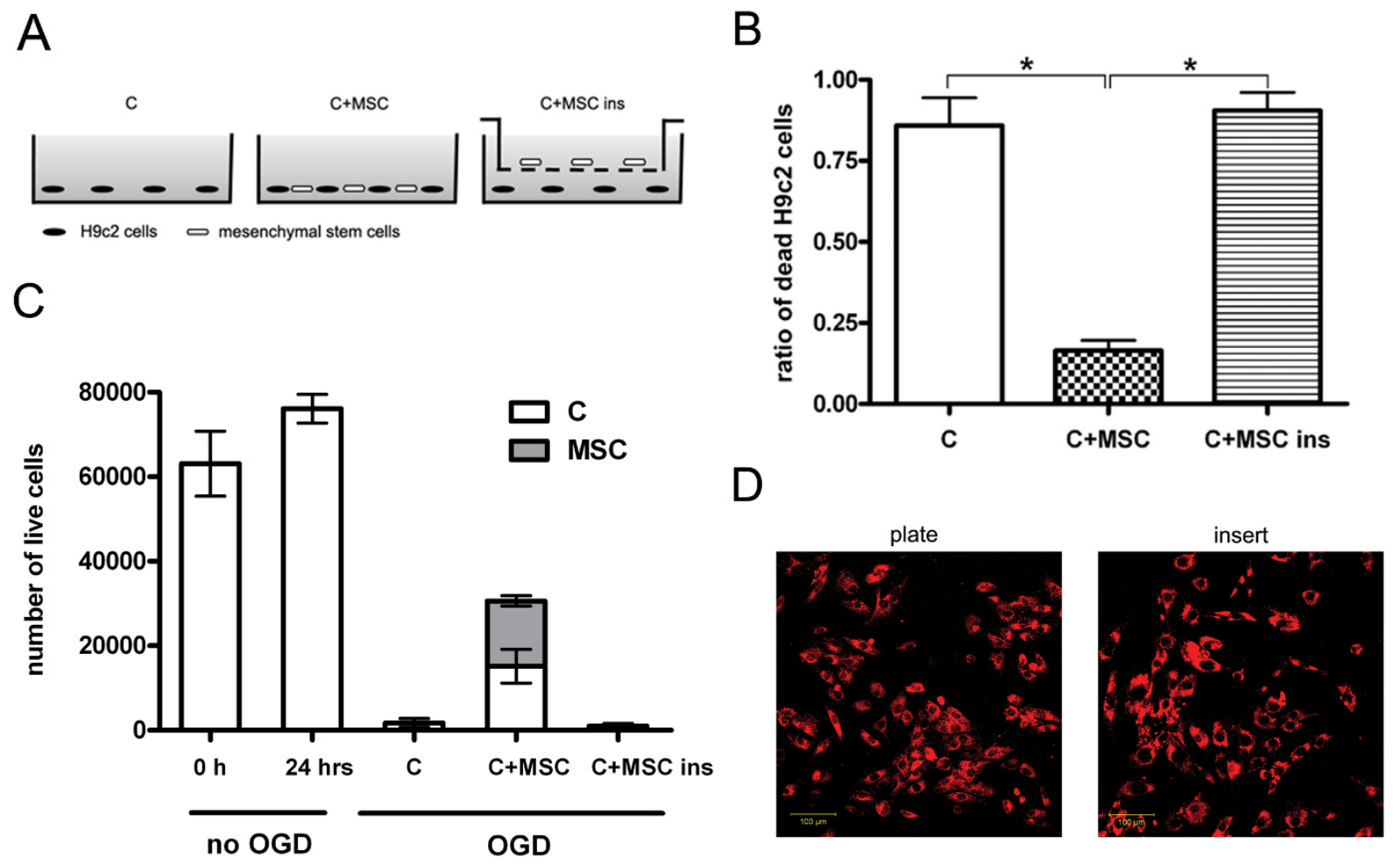

Figure 3 Co-cultivation of $\mathbf{H} 9 \mathbf{c} 2$ cells with MSCs decreased cell death. (A) Experimental layouts after in vitro ischemia. (B) The ratio of dead H9c2 cells was significantly smaller when MSCs were added after OGD ( $0.85 \pm 0.086$ vs. $0.16 \pm 0.035, n=5)$, but MSCs added in cell culture inserts did not decrease significantly the ratio of dead H9c2 cells $(0.90 \pm 0.055, n=5)$. Data represent mean \pm SEM. ${ }^{*} p<0.05 C+M S C$ vs. C and C+MSC vs. C+MSC ins. (C: H9c2 cells only; C+MSC: H9c2 cells and MSCs; C+MSC ins: H9c2 cells and MSCs in cell culture inserts) (C) Absolute number of live H9c2 cells before and after OGD shows that before OGD the H9c2 cells were close to confluence $(63,120 \pm 7,694)$ and there was little increase in cell numbers during the next 24 hours if the cells were left to grow without OGD $(76,116 \pm 3,396)$. 24 hours after OGD the number of viable cells was very low when cultured alone or with MSCs in cell insert $(1,757 \pm 1,081$ and $990 \pm 608$ respectively), which was significantly increased $(15,174 \pm 3,975)$ if MSCs added directly. (D) MSCs labeled with Vybrant DiD were growing on cell culture inserts in the same manner as under normal culture conditions after 24 hours of cultivation. Scale bar represents $100 \mu \mathrm{m}$.

normal, non-ischemic conditions among H9c2 cells and MSCs we co-cultured these cells without OGD and found that such phenomenon also occurs among healthy cells. Flow cytometry analysis showed beside $59.42 \%$ of DiOlabeled H9c2 cells and $30.1 \%$ of DiD-labeled MSCs also $8.14 \%$ of double labeled cells. However, according to the forward and side scatter plot the distribution demonstrates that most of the double labeled cells are the same size as H9c2 cells or MSCs, suggesting that these cells are picking up the other marker through direct cell-to-cell contact (Figure 6C and 6D).

We also considered the possibility that MSCs may incorporate cell debris and thus acquire double labeling of fluorescent dyes. During the observations performed with time-lapse video microscopy we frequently saw that healthy cells contacted and moved around cell debris and apoptotic bodies in the culture dish, however, phagocytosis was not observed. The cells which contacted differen- tially stained cell debris did not pick up any fluorescent signal from the other, indicating that the double labeling of cells arose from a specific and controlled mechanism rather than cross-contamination. This is further strengthened by the observation that not all cell-to-cell connection resulted in dye transfer. (additional file 4: video4.mov)

\section{Discussion}

We report that healthy mesenchymal stem cells are capable of rescuing post-ischemic cardiomyoblasts from cell death through a mechanism not yet implicated in the effects of stem cells after ischemic conditions. Thus, the beneficial effect of stem cell grafting may be based not only on improved neovascularisation and replacement of lost cells but on rescuing the damaged cells of the host as well. 


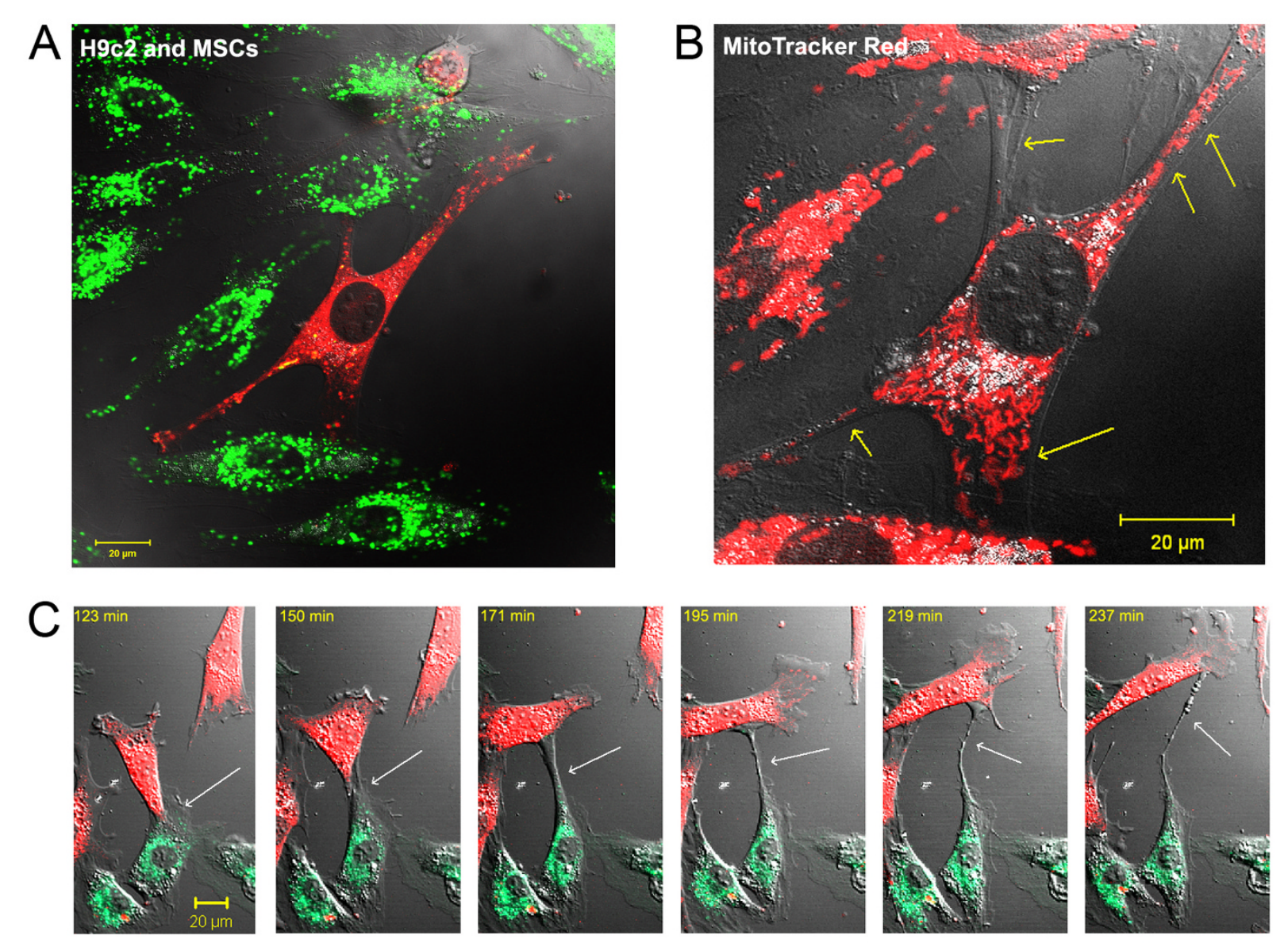

Figure 4 Formation of intercellular connections after OGD. (A) Nanotubular network formation was observed among DiO-labeled cardiomyoblasts (green) and DiD-labeled MSCs (red) after 24 hours of co-culture. (B) MitoTracker staining (red) revealed active mitochondria in the nanotubular network (yellow arrows). (C) Time lapse pictures of the formation of a nanotube between a DiO-labeled cardiomyoblast (green) and DiD-labeled stem cell (red).

The most likely explanation of the beneficial effects of MSC co-culture is that these cells improve the chances of the damaged $\mathrm{H} 9 \mathrm{c} 2$ cells to restore their function and prevent later cell death. Ethidium homodimer has been shown to stain not only dead but damaged cells as well [23]. Thus, although most H9c2 cells were stained by ethidium homodimer after OGD (Figure 1B), many cells were probably only reversibly damaged. An alternative explanation of our results could be an increased replication of surviving H9c2 cells. However, the nearly ten-fold difference in the number of viable $\mathrm{H} 9 \mathrm{c} 2$ cells between our experimental groups $24 \mathrm{hr}$ after OGD (Figure 3C) and the normal doubling time of these cells make this possibility unlikely to explain the difference.

The used in vitro ischemia model demonstrates that the beneficial effects of MSC co-culture seem to be dependent on direct cell-to-cell connections and intercellular nanotubes.
Nanotube formation has already been shown to occur among endothelial progenitor cells, cardiomyocytes $[20,24]$, immune cells and other lineages [25,26]. The characterization of nanotubes revealed that these filaments contain actin and in some cases, microsomes or mitochondria [27]. We found that this phenomenon occurs frequently between cardiomyoblasts and mesenchymal stem cells. Stem cells failed to rescue post-ischemic cardiomyoblasts when intercellular connections were blocked by a physical barrier. These observations indicate that intercellular connections work toward the survival of cells both during and after ischemia, however, the underlying mechanisms may be slightly different.

One plausible mechanism for the rescuing effect is that transplanted cells improve regeneration through secreting paracrine factors [14,28-31]. However, results from our experiments with the plate insert show that paracrine factors secreted by the cells are probably too low in our 

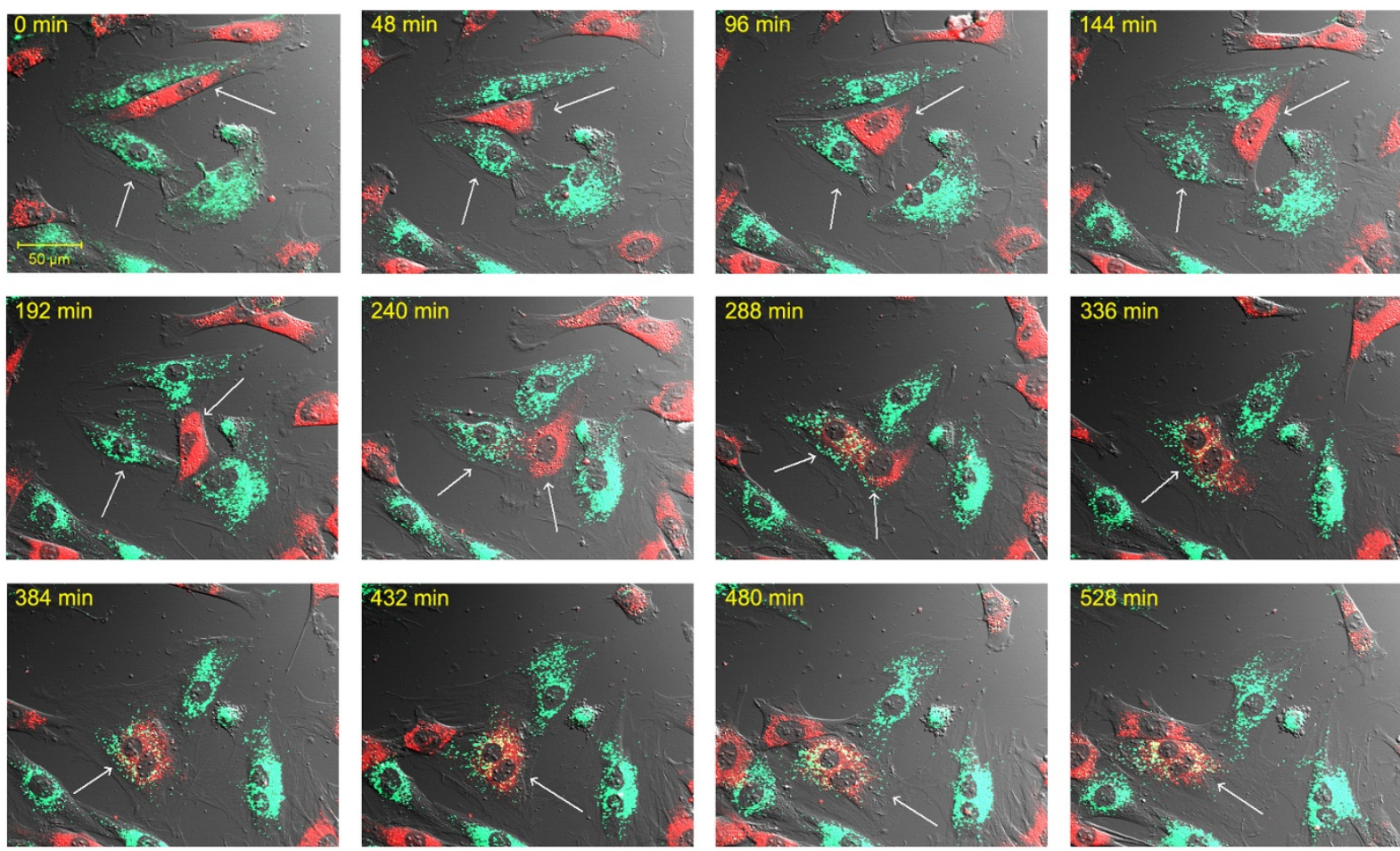

Figure $\mathbf{5}$ Cell fusion of a $\mathbf{H} \mathbf{9} \mathbf{c} 2$ cell and a mesenchymal stem cell. The time lapse pictures demonstrate steps of the fusion of a H9c2 cell (green) and a mesenchymal stem cell (red). Fused cells with double nuclei exhibit a combined yellow staining.

system to have any beneficial effect on these severely damaged cells. This in vitro experimental setup allows the investigation of cell-to-cell contacts, however, it cannot rule out that paracrine effects play a significant role in a more physiological in vivo setting. The time frame of the experimental protocol is also important. In our experiments we added the cells at an early time point and terminated the experiment before significant differentiation can occur. During a later time point the effect of paracrine factors is probably much more important especially in the differentiation process as shown by several other authors $[6,11]$.

Cell fusion is another phenomenon which is frequently observed in co-culture studies and in some cases, in in vivo experiments as well $[15,32,33]$. Several studies have shown that cell fusion can result in transdifferentiation, thus offering an alternative mechanism by which grafted cells improve the infarcted myocardium. Using videomicroscopy we also found several double labeled, double nuclei cells indicative of cell fusion. However, cell fusion showed high variations among different culture and detection techniques, and therefore extensive cell fusion as an in vitro artefact cannot be ruled out $[14,34,35]$. During our investigations we only observed a few unques- tionable cell fusions which cannot account for the rescue of the high number of damaged cardiomyoblasts [36].

We also found double labeled cells without double nuclei in the co-culture of cardiomyoblasts and stem cells after 24 hours. The double labeling of these cells may be the result of direct cell-to cell connections. During these periods of connection, cells are able to exchange membrane parts and Vybrant dye molecules can drift from one cell to another. Movement of dye molecules from one cell to another through gap junction connections is precluded because the lipophilic Vybrant dyes are high molecular weight stains and cannot permeate through gap junctions [34]. Driesen et al. [19] showed that low molecular weight tracers such as calcein-AM get from one cell to another through gap junctions, and high molecular weight tracers by partial cell fusion, thus the conclusion may be drawn that dye transfers after 24 hours in our experiment are most probably the results of direct cell-to-cell connections. Still, gap junctions may create an opportunity for grafted cells to interact with the host tissues $[37,38]$. In the present experimental model most of cell-to-cell interactions were short-lived tubular connections, which formed a constantly changing web between the two investigated cell types. 


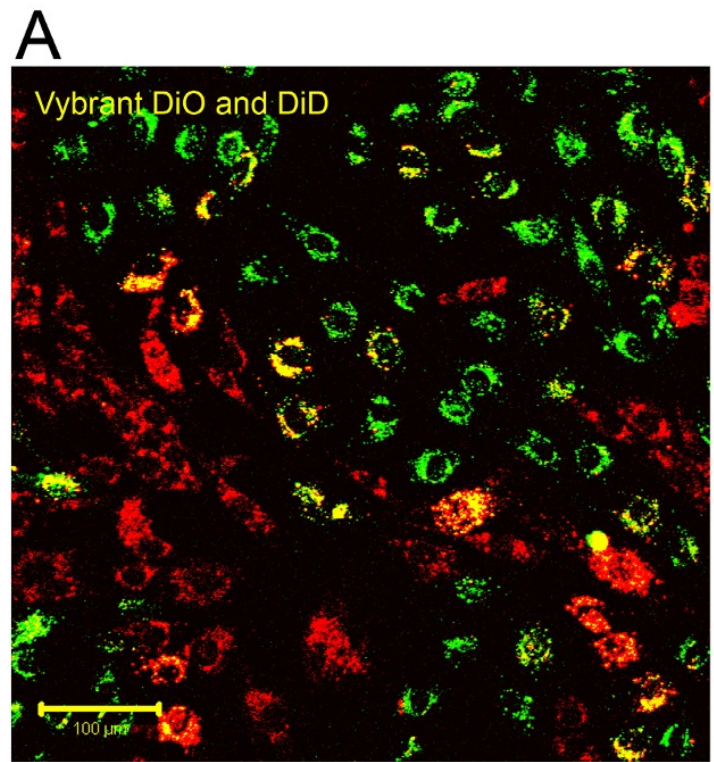

\section{B}
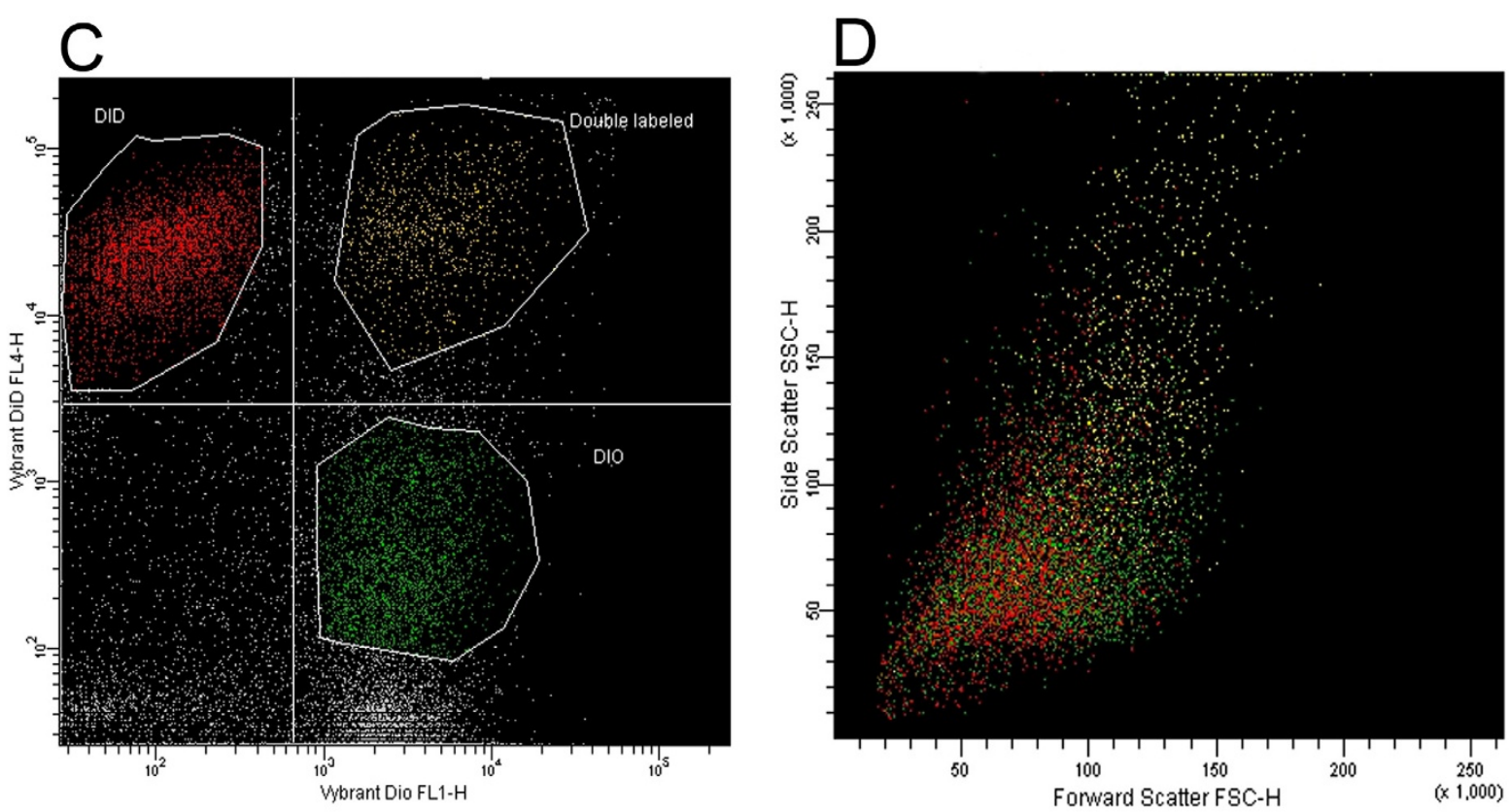

Figure 6 Co-culture of H9c2 and stem cells in normal conditions. (A) Cardiomyoblasts (green) and MSCs (red) after one day co-cultivation. (B) A representative double labeled cell with double nuclei (nuclei were stained with Hoechst). (C) DiO-labeled cardiomyoblasts (green) and DiD-labeled MSCs (red) analyzed with flow cytometry after one day co-cultivation. We found three different cell populations: 59.42\% of DiO-labeled H9c2 cells, $30.1 \%$ of DiD-labeled MSCs and $8.14 \%$ of double labeled cells. (D) The distribution according to the forward scatter plot demonstrates that several double labeled yellow cells are mostly the same size as the green H9c2 cells or the red MSCs disapproving complete cell fusion.

Our experimental model was devised to investigate acute effects with high temporal and spatial resolution, therefore ruling out differentiation, which occurs over time. Moreover, an in vitro transplantation model in a cell culture system cannot mimic the 3-dimensional tissue where cell-to-cell connections are different. These circumstances obviously limit the conclusions drawn from our results. On the other hand, this experimental setting was necessary and favorable to investigate short-term cellular interactions.

\section{Conclusions}

The present study highlights that stem cell grafting may be beneficial through an acute, direct mechanism which saves damaged cardiomyoblasts. Novel grafting protocols can harness this effect, which raises the possibility that 
stem cells given early and locally can preserve heart tissue rather than simply help to replace what is already lost.

\section{Additional material}

\section{Additional file 1 Follow up of 150 minutes long OGD on cardiomyo- blasts with time lapse video microscopy. \\ Additional file 2 Nanotubular network formation among DiO-labeled cardiomyoblasts (green) and DiD-labeled MSCs (red) after 24 hours of co-culture.}

Additional file 3 Time lapse video microscopy pictures demonstrates fusion of a $\mathrm{H} 9 \mathrm{c} 2$ cell (green) and a mesenchymal stem cell (red).

Additional file 414 hours of time lapse video microscopy of $\mathrm{H} 9 \mathrm{c2}$ cells (green) and MSCs (red) after OGD.

\section{Authors' contributions}

ACS and ZSL conceived the study. ACS completed the majority of the confocal microscopy experiments, made the flow cytometry measurements, performed statistical analysis, and helped draft the manuscript. EP helped draft the manuscript and performed statistical analysis. EMH participated in the flow cytometer measurements. $\mathrm{KL}$ participated in the time lapse video microscopy experiments and helped draft the manuscript. In addition to collaborating on the conception of the study, ZSL participated in the study design, provided coordination among the researchers and experiments, and helped draft the manuscript. All authors read and approved the final manuscript.

\section{Acknowledgements}

This work was supported by OTKA (Hungarian Scientific Research Fund) D45933, T049621, TÉT (Hungarian Science and Technology Foundation) A4/04 and Arg-17/2006, Bolyai, Öveges Fellowships and TÁMOP 4.2.2-08/1/KMR2008-0004. We would like to thank Dr. Ferenc Uher for providing the mouse mesenchymal stem cells. We are grateful to Nancy Busija for copyediting the manuscript and we thank David Busija and Márk Kollai for critically revising the manuscript.

\section{Author Details}

Institute of Human Physiology and Clinical Experimental Research, Semmelweis University, H-1094, Tüzoltó utca 37-47, Budapest, Hungary

Received: 2 September 2009 Accepted: 20 April 2010

Published: 20 April 2010

\section{References}

1. Dayer M, Cowie MR: Heart failure: diagnosis and healthcare burden. Clin Med 2004, 4(1):13-18.

2. Kesteloot H, Sans S, Kromhout D: Dynamics of cardiovascular and allcause mortality in Western and Eastern Europe between 1970 and 2000. Eur Heart J 2006, 27(1):107-113.

3. Antonio Giordano UGIRM: From the laboratory bench to the patient's bedside: An update on clinical trials with mesenchymal stem cells. Journal of Cellular Physiology 2007, 211(1):27-35

4. Stefan Bajada IMJBRNA: Updates on stem cells and their applications in regenerative medicine. Journal of Tissue Engineering and Regenerative Medicine 2008, 2(4):169-183.

5. Jawad H, Lyon AR, Harding SE, Ali NN, Boccaccini AR: Myocardial tissue engineering. BrMed Bull 2008, 87(1):31-47.

6. Dai W, Hale SL, Martin BJ, Kuang J-Q, Dow JS, Wold LE, Kloner RA: Allogeneic Mesenchymal Stem Cell Transplantation in Postinfarcted Rat Myocardium: Short- and Long-Term Effects. Circulation 2005, 112(2):214-223.

7. Orlic D, Kajstura J, Chimenti S, Jakoniuk I, Anderson SM, Li B, Pickel J, McKay R, Nadal-Ginard B, Bodine DM, et al.: Bone marrow cells regenerate infarcted myocardium. Nature 2001,410(6829):701.

8. Collins SD, Baffour R, Waksman R: Cell therapy in myocardial infarction. Cardiovascular Revascularization Medicine 2007, 8(1):43.

9. Dimmeler S, Burchfield J, Zeiher AM: Cell-Based Therapy of Myocardial Infarction. Arterioscler Thromb Vasc Biol 2007.
10. Sadat S, Gehmert S, Song YH, Yen Y, Bai X, Gaiser S, Klein H, Alt E: The cardioprotective effect of mesenchymal stem cells is mediated by IGF-I and VEGF. Biochem Biophys Res Commun 2007, 363(3):674-679.

11. Kinnaird T, Stabile E, Burnett MS, Lee CW, Barr S, Fuchs S, Epstein SE: Marrow-derived stromal cells express genes encoding a broad spectrum of arteriogenic cytokines and promote in vitro and in vivo arteriogenesis through paracrine mechanisms. Circ Res 2004, 94(5):678-685

12. Masuda S, Shimizu T, Yamato M, Okano T: Cell sheet engineering for heart tissue repair. Adv Drug Deliv Rev 2008, 60(2):277-285.

13. Yoon J, Shim WJ, Ro YM, Lim DS: Transdifferentiation of mesenchymal stem cells into cardiomyocytes by direct cell-to-cell contact with neonatal cardiomyocyte but not adult cardiomyocytes. Ann Hematol 2005, 84(11):715-721.

14. Menasche P: You Can't Judge a Book by Its Cover. Circulation 2006 113(10):1275-1277.

15. Nygren JM, Jovinge S, Breitbach M, Sawen P, Roll W, Hescheler J, Taneera J, Fleischmann BK, Jacobsen SE: Bone marrow-derived hematopoietic cells generate cardiomyocytes at a low frequency through cell fusion but not transdifferentiation. Nat Med 2004, 10(5):494-501.

16. Murry CE, Soonpaa MH, Reinecke H, Nakajima H, Nakajima HO, Rubart M, Pasumarthi KB, Virag Jl, Bartelmez SH, Poppa V, et al:: Haematopoietic stem cells do not transdifferentiate into cardiac myocytes in myocardial infarcts. Nature 2004, 428(6983):664-668.

17. Alvarez-Dolado M, Pardal R, Garcia-Verdugo JM, Fike JR, Lee HO, Pfeffer K, Lois C, Morrison SJ, Alvarez-Buylla A: Fusion of bone-marrow-derived cells with Purkinje neurons, cardiomyocytes and hepatocytes. Nature 2003, 425(6961):968.

18. Kajstura J, Rota M, Whang B, Cascapera S, Hosoda T, Bearzi C, Nurzynska D, Kasahara $\mathrm{H}$, Zias $\mathrm{E}$, Bonafe $\mathrm{M}$, et al:: Bone marrow cells differentiate in cardiac cell lineages after infarction independently of cell fusion. Circ Res 2005, 96(1):127-137.

19. Driesen RB, Dispersyn GD, Verheyen FK, Eijnde SM van den, Hofstra L, Thone F, Dijkstra P, Debie W, Borgers M, Ramaekers FC: Partial cell fusion: a newly recognized type of communication between dedifferentiating cardiomyocytes and fibroblasts. Cardiovasc Res 2005, 68(1):37-46.

20. Plotnikov EY, Khryapenkova TG, Vasileva AK, Marey MV, Galkina SI, Isaev NK, Sheval EV, Polyakov VY, Sukhikh GT, Zorov DB: Cell-to-cell cross-talk between mesenchymal stem cells and cardiomyocytes in co-culture. J Cell Mol Med 2008, 12(5A):1622-1631.

21. Tropel $P$, Noel D, Platet N, Legrand P, Benabid AL, Berger F: Isolation and characterisation of mesenchymal stem cells from adult mouse bone marrow. Exp Cell Res 2004, 295(2):395-406.

22. Urbán VS, Kiss J, Kovács J, Gócza E, Vas V, Edot, Monostori v, Uher F: Mesenchymal Stem Cells Cooperate with Bone Marrow Cells in Therapy of Diabetes. Stem Cells 2008, 26(1):244-253.

23. Kaplan LD: The analysis of articular cartilage after thermal exposure: "Is red really dead?". Arthroscopy 2003, 19(3):310-313.

24. Koyanagi M, Brandes RP, Haendeler J, Zeiher AM, Dimmeler S: Cell-to-Cell Connection of Endothelial Progenitor Cells With Cardiac Myocytes by Nanotubes: A Novel Mechanism for Cell Fate Changes? Circ Res 2005, 96(10):1039-1041.

25. Onfelt B, Nedvetzki S, Yanagi K, Davis DM: Cutting edge: Membrane nanotubes connect immune cells. JImmuno/ 2004, 173(3):1511-1513.

26. Onfelt B, Purbhoo MA, Nedvetzki S, Sowinski S, Davis DM: Long-distance calls between cells connected by tunneling nanotubules. SciSTKE 2005, 2005(313):pe55

27. Spees $\mathrm{J}$, Olson SD, Whitney MJ, Prockop DJ: Mitochondrial transfer between cells can rescue aerobic respiration. Proc Natl Acad Sci USA 2006, 103(5):1283-1288

28. Gnecchi M, Zhang Z, Ni A, Dzau VJ: Paracrine Mechanisms in Adult Stem Cell Signaling and Therapy. Circ Res 2008, 103(11):1204-1219.

29. Paul WMF: Paracrine Effects of Cell Transplantation: Modifying Ventricular Remodeling in the Failing Heart. Seminars in thoracic and cardiovascular surgery 2008, 20(2):87.

30. Takahashi M, Li TS, Suzuki R, Kobayashi T, Ito H, Ikeda Y, Matsuzaki M, Hamano K: Cytokines produced by bone marrow cells can contribute to functional improvement of the infarcted heart by protecting cardiomyocytes from ischemic injury. Am J Physiol Heart Circ Physiol 2006, 291(2):H886-893. 
31. Uemura R, Xu M, Ahmad N, Ashraf M: Bone marrow stem cells prevent left ventricular remodeling of ischemic heart through paracrine signaling. Circ Res 2006, 98(11):1414-1421.

32. Ishikawa F, Shimazu H, Shultz LD, Fukata M, Nakamura R, Lyons B, Shimoda K, Shimoda S, Kanemaru T, Nakamura K, et al:: Purified human hematopoietic stem cells contribute to the generation of cardiomyocytes through cell fusion. Faseb J 2006, 20(7):950-952

33. Lacza Z, Horvath E, Busija DW: Neural stem cell transplantation in cold lesion: a novel approach for the investigation of brain trauma and repair. Brain Research Protocols 2003, 11 (3):145.

34. Garbade J, Schubert A, Rastan AJ, Lenz D, Walther T, Gummert JF, Dhein S, Mohr F-W: Fusion of bone marrow-derived stem cells with cardiomyocytes in a heterologous in vitro model. European Journal of Cardio-Thoracic Surgery 2005, 28(5):685.

35. Kajstura J, Rota M, Whang B, Cascapera S, Hosoda T, Bearzi C, Nurzynska D, Kasahara H, Zias E, Bonafe M, et al:: Bone Marrow Cells Differentiate in Cardiac Cell Lineages After Infarction Independently of Cell Fusion. Circ Res 2005, 96(1):127-137.

36. Rose RA, Jiang H, Wang X, Helke S, Tsoporis JN, Gong N, Keating SC, Parker $\mathrm{TG}$, Backx PH, Keating A: Bone marrow-derived mesenchymal stromal cells express cardiac-specific markers, retain the stromal phenotype, and do not become functional cardiomyocytes in vitro. Stem Cells 2008, 26(11):2884-2892

37. Horackova M, Arora R, Chen R, Armour JA, Cattini PA, Livingston R, Byczko $Z$ : Cell transplantation for treatment of acute myocardial infarction: unique capacity for repair by skeletal muscle satellite cells. Am J Physiol Heart Circ Physiol 2004, 287(4):H1599-1608.

38. Xu M, Wani M, Dai YS, Wang J, Yan M, Ayub A, Ashraf M: Differentiation of bone marrow stromal cells into the cardiac phenotype requires intercellular communication with myocytes. Circulation 2004, 110(17):2658-2665.

doi: 10.1186/1471-2121-11-29

Cite this article as: Cselenyák et al., Mesenchymal stem cells rescue cardiomyoblasts from cell death in an in vitro ischemia model via direct cell-to-cell connections BMC Cell Biology 2010, 11:29

Submit your next manuscript to BioMed Centra and take full advantage of:

- Convenient online submission

- Thorough peer review

- No space constraints or color figure charges

- Immediate publication on acceptance

- Inclusion in PubMed, CAS, Scopus and Google Scholar

- Research which is freely available for redistribution

Submit your manuscript at www.biomedcentral.com/submit
C Biomed Central 